\title{
Correspondence
}

The Editor,

Journal of Glaciology

SIR,

\section{What is the major reason for glacier retreat on Yulong mountain, China?}

Yulong mountain is located in the Hengduan mountain range in Yunnan Province, China $\left(27^{\circ} 10^{\prime}-27^{\circ} 40^{\prime} \mathrm{N}, 100^{\circ} 07^{\prime}-100^{\circ} 10^{\prime}\right.$ E), $25 \mathrm{~km}$ north of Lijiang (Fig. 1). It extends $35 \mathrm{~km}$ from south to north and $13 \mathrm{~km}$ from west to east. With a highest peak of $5596 \mathrm{~m}$, it is the southernmost glacierized area in Eurasia. The 19 glaciers on Yulong mountain, which have a total area of $11.61 \mathrm{~km}^{2}$, are controlled by the southern Asian monsoon climate. They are characterized by large accumulation and ablation, relatively high ice temperature, basal sliding and the rapid movement characteristic of subtropical temperate glaciers ( $\mathrm{Li}$ and $\mathrm{Su}, 1996)$. Their dominant feature is that they are very sensitive to climatic change ( $\mathrm{Su}$ and Shi, 2000).

In the huge glacier-covered areas of western China, there are more than 8600 temperate glaciers, located mainly in Yunnan, Sichuan and southeastern Tibet (He and others, 2000, in press). Since 1996, the Lijiang-Yulong region has been developed into the largest glacier park in China, because of its special location, mild climate conditions and beautiful scenery. This has been accompanied by rapidly increased human activity in the region. Accordingly, more and more attention has been paid by scientists and various societies to problems related to the region's environment, resources and sustainable development.

Since the 1950s, global climatic change has had significant effects on China's monsoonal temperate-glacier region. Data indicate that in the Lijiang-Yulong region the average annual temperature during the period $1982-2001$ was $0.2^{\circ} \mathrm{C}$ higher than for 1962-81, and, in addition, the average annual temperature during the years $1998-2001$ was $0.6^{\circ} \mathrm{C}$ higher than for 1982-97. In Zhongdian, close to Lijiang, the average annual temperature during the 20 years $1982-$ 2001 increased by $0.7^{\circ} \mathrm{C}$ compared with the previous 20 years, $1962-81$. The average annual temperature during

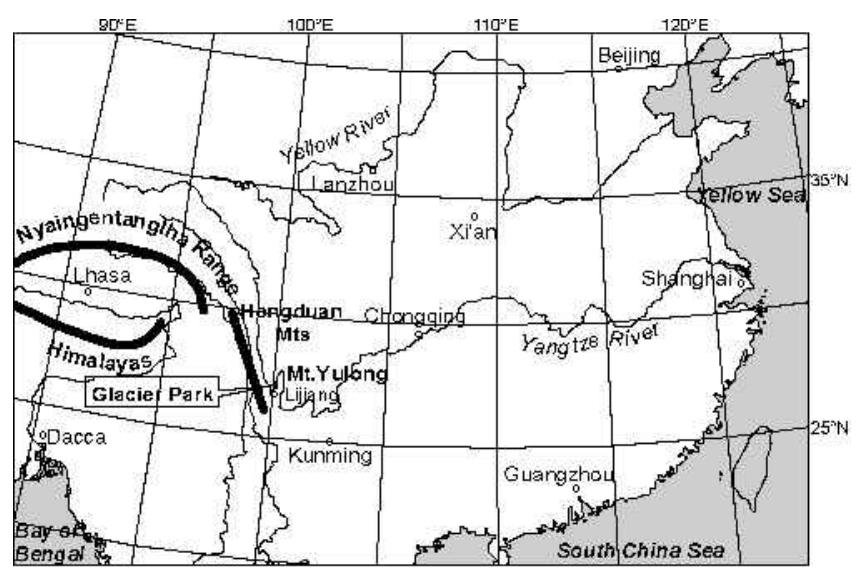

Fig. 1. Location of Yulong mountain and the glacier park, near Lijiang in China. the most recent 4 years $(1998-2001)$ was $0.8^{\circ} \mathrm{C}$ higher than for 1982-97, demonstrating a rapid warming trend in the area (Jones and others, 1999; He and others, 2002b, in press). Against this climatic background, the speed of glacial changes on Yulong mountain has increased, with increased glacier ablation, retreat of the glacier margins, reduction of the glaciers' areas and a rise of the snowline. As a distinct indicator of climate change, the terminus of Baishui glacier No. 1, the largest glacier on Yulong mountain, retreated by $100 \mathrm{~m}$ during the 4 years 1998-2002, and the glacier's size and thickness have decreased at the same time ( $\mathrm{He}$ and others, 2000, in press).

According to local government statistics, the number of tourists in the Yulong area rose from about 400000 in 1998 to 1.2 million in 2002, a rate of increase of 200000 per year. Local government and tourism agencies in Lijiang are greatly concerned by this phenomenon, as it will have important effects on the region's natural environment and thereby tourism business. Of course, their concern is shared by tourists, who expect the mountain to be snow-carpeted and to retain its beautiful scenery for ever. Why are the glaciers on Yulong mountain retreating? There are two popular explanations. Some have suggested that the main cause is the body heat emitted by the increasing number of visitors to the glacier. Another view is based on the development of tourism in the region, which has led to more facilities, such as roads, hotels, cableways and communication lines, with a large increase in both the number of vehicles and the "floating population". All these factors, it is argued, are likely to have impacts on the local natural environment and ecosystems, leading to a "heat island effect". Combined with an exponential growth in greenhouse gases, such as atmospheric $\mathrm{CO}_{2}$, this effect may directly or indirectly result in increased glacier melting and recession. Considering these questions, we have carried out a series of detailed observations and studies between 2000 and 2002 dealing with the recent climatic and glacier variations in the region (He and others, 2000, 2002a, b, in press).

To better understand the first viewpoint, an investigation of visitors to the glacier was carried out. This confirmed that they are only permitted to view the glacier at some specified locations near the margin, 4500-4700 m a.s.l. Because all visitors dress in weatherproof clothes, we can deduce that the body heat is so small that it can be ignored: the small amount of body-released heat will be removed by the continuous strong wind on the mountain. However, the second viewpoint appears to be more scientific. A "heat island effect" may increase local atmospheric heat to some extent, and thus lead to increased snow/ice melting, resulting in glacier retreat. It is calculated that only $3 \%$ of the total area of Yulong mountain has been used for tourism, and the number of tourists visiting the glacier is now restricted to 3000 per day. The local government and related authorities have taken many measures to protect and reinstate natural ecosystems and resources, such as planting more trees and grasses, removing local residents from the tourism area, and building reservoirs to increase the coverage of vegetation and water. At present, tourism is the major economic element in the Lijiang region, which has no heavy industry. In view of these facts, the "heat 
island effect" is not a principal reason for glacier retreat, and its impact is estimated to be small compared with that of climatic warming (Zhao and others, unpublished). Further work is needed to quantify this effect.

We believe that the most important cause of glacier retreat on Yulong mountain is global climate warming. Intergovernmental Panel on Climate Change reports (McCarthy and others, 2001) indicate that the mean annual temperature in the Northern Hemisphere rose by $0.4^{\circ} \mathrm{C}$ between the $1960 \mathrm{~s}$ and 1980s. On the Tibetan Plateau during the same period, the temperature rose by about $0.5^{\circ} \mathrm{C}$, and this was followed by an accelerated warming rate, with a rise of about $1^{\circ} \mathrm{C}$ between the 1990s and the present. This is similar to the warming trend observed in the Lijiang-Yulong region. Thus, it is confirmed that the monsoon temperate glaciers are the most sensitive indicator of climate change. Although the mean annual temperature increment is smaller in China's monsoonal temperate-glacier region than in other regions, the rate of glacier retreat is significantly higher than in other regions, the reduction in size since the Little Ice Age being about $40 \%$, compared with about $15-25 \%$ elsewhere (Su and Shi, 2000). The lower latitude at which the glaciers are located, and the smaller glacier area, increases their sensitivity to climate change. Those glaciers on Yulong mountain with the lowest latitude and smallest area have reduced in size by $60 \%$ from the Little Ice Age to the present (He and others, in press). It is evident that there is a close relation between atmospheric temperature and glacier retreat on Yulong mountain. Therefore we conclude that global warming is the most important reason for glacier retreat in the LijiangYulong region. The present climate warming is unchangeable. Humans should do their best to protect the environment and to maintain the balance of ecosystems, in order to make the "heat island effect" on the region as small as possible.

\section{AGKNOWLEDGEMENTS}

The research work is supported by the Hundred Talents Project (CAS2002-43), a special project of Famous Young Scientists and a fund (40071023) from the Chinese Natural Science Foundation, as well as the Knowledge-Innovation Programs (210506, 210019 and KZCX2-301), Cold and Arid
Regions Environmental and Engineering Research Institute, Chinese Academy of Sciences.

Cold and Arid Regions Environmental and Engineering Research Institute,

HE YUANQING GU JUAN

Chinese Academy of Sciences,

Lanzhou 730000, China

E-mail:yqhe@ns.lzb.ac.cn

Department of Geography,

ZHANG DIAN

The University of Hong Kong,

Pokfulam Road,

Hong Kong, China

\section{April 2003}

\section{REFERENCES}

He Yuanqing, Yao Tandong and Yang Meixue. 2000. [Spatial features of glacial hydro-chemistry and recent variations of a Chinese temperate glacier on Mt. Yulong.] [ 7. Mount. Sci.], 18(6), 481-488. [In Chinese with English summary.

He Yuanqing, W. H. Theakstone, Yao Tandong, Chen Tuo and D. D. Zhang. 2002a. The irregular pattern of isotopic and ionic signals in the typical monsoon temperate-glacier area, Yulong mountain, China. Ann. Glaciol., 35, 167-174.

He Yuanqing, Yao Tandong, W. H. Theakstone and Yang Meixue. 2002b. Recent climatic significance of chemical signals in a shallow firn core from an alpine glacier in the South-Asia monsoon region. 7. Asian Earth Sci., 20(3), 289-296.

He Yuanqing, Zhang Zhonglin, W. H. Theakstone, Chen Tuo, Yao Tandong and Pang Hongxi. In press. Changing features of the climate and glaciers in China's monsoonal temperate-glacier region since the Little Ice Age. F. Geophys. Res.

Jones, P. D., M. New, D. E. Parker, S. Martin and I. G. Rigor. 1999. Surface air temperature and its changes over the past 150 years. Rev. Geophys, 37(2), 173-199.

Li Jijun and Su Zhen, eds. 1996. [Glaciers in the Hengduanshan] Beijing, Science Press. [In Chinese with English summary.]

McCarthy, J. J., O. F. Canziani, N. A. Leary, D. J. Dokken and K. S. White, eds. 2001. Climate change 2001: impacts, adaptation, and vulnerability. Cambridge, etc., Cambridge University Press. Intergovernmental Panel on Climate Change. (Contribution of Working Group II to the Third Assessment Report.)

Su Zhen and Shi Yafeng. 2000. [Response of monsoonal temperate glaciers in China to global warming since the Little Ice Age.] F. Glaciol. Geocryol., 22(3), 223-229. [In Chinese with English summary.]

Zhao, X., B. Zheng, Z. Xiao and T. Li. Unpublished.[A report on tourism resources, planning and developing of the glacier park in Mt. Yulong.] Beijing, Chinese Academy of Sciences. Institute of Geology. [In Chinese.] 